\title{
Severe Hyperthermia Induces Apoptosis Mediated by Caspases Activation and Suppression of Hsp90a Expression in Osteosarcoma Cells
}

\author{
Mohammed Ali Nashiry ${ }^{1}$, Gabriele Ruth Anisah Froemming, ${ }^{2, *}$, Yeap Swee Keong ${ }^{3}$, \\ Aletza Binti Mohd Ismail ${ }^{4}$, Aisha Mohd Din ${ }^{5}$, Alyaa Mahmood Al-Khateeb ${ }^{4,6}$ \\ ${ }^{1}$ Institute of Medical Molecular Biotechnology, Faculty of Medicine, Universiti Teknologi MARA, 47000 Sungai Buloh, Selangor, Malaysia \\ ${ }^{2}$ Faculty of Medicine and Allied Health Sciences, University Malaysia Sarawak, 94300 Kota Samarahan, Sarawak, Malaysia \\ ${ }^{3}$ China-ASEAN College of Marine Sciences, Xiamen University Malaysia, Jalan Sunsuria, Bandar Sunsuria, 43900 Sepang, Selangor, Malaysia \\ ${ }^{4}$ Faculty of Medicine, Universiti Teknologi MARA, 47000 Sungai Buloh, Selangor, Malaysia \\ ${ }^{5}$ Department of Basic Sciences, Faculty of Health Sciences, Universiti Teknologi MARA Cawangan Selangor, Puncak Alam, 42300, Malaysia \\ ${ }^{6}$ I-PPerForM, Universiti Teknologi MARA (UiTM), Sungai Buloh, Selangor, Malaysia \\ *Corresponding author. E-mail: gabi_anisahf@yahoo.com
}

Received date: Oct 15, 2018; Revised date: Jan 16, 2019; Accepted date: Jan 22, 2019

\section{Abstract}

B ACKGROUND: Hyperthermia is used as an adjuvant treatment to sensitize cancer cells to subsequent radiotheraphy or chemotherapy. The aim of this study was to study the effect of severe hyperthermia on osteosarcoma cells and its underlying causes.

METHODS: Short-term $(1 \mathrm{~h})$ severe hyperthermia $\left(45^{\circ} \mathrm{C}\right)$ was applied to osteoblast-like osteosarcoma cells (MG-63) and the heat shock response and cell death mechanisms were investigated after recovery at $37^{\circ} \mathrm{C}$ for $72 \mathrm{~h}$.

RESULTS: Cell viability was significantly reduced $(p<0.05)$ and apoptosis was significantly induced by severe hyperthermia in MG-63 cells $(p<0.001)$. Caspase 3/7, 4 and 12 activities were significantly increased after $72 \mathrm{~h}$ of recovery at $37^{\circ} \mathrm{C}$, indicating that severe hyperthermia

\section{Introduction}

Osteosarcoma, a primary malignancy of growing bones, arises mainly from the metaphysis of the long bones in adolescents and young adults, with an incidence of 0.030.2 per 100,000 population yearly.(1-3) However, as it mainly arises in children and young adults, early diagnosis and treatment are crucial. Rapid developments in combined chemotherapy have improved the 5-year survival rate of induced endoplasmic reticulum (ER) stress and apoptosis $(p<0.05)$. Heat shock protein 90 alpha $(\mathrm{Hsp} 90 \alpha)$ was significantly down regulated at the protein level after recovery, in association with apoptosis induction $(p<0.01)$. Additionally, caspase 8 and 9 were activated, possibly as a result of ER stress or other stimuli while, B-cell leukemia 2 family protein (BCL-2) mRNA was down regulated $(p<0.01)$.

CONCLUSION: Severe hyperthermia could cause prolonged cell cytotoxicity by inducing apoptosis in association with inhibition of Hsp90a. This indicates the therapeutic potential of severe hyperthermia for the treatment of osteosarcoma.

KEYWORDS: hyperthermia, apoptosis, endoplasmic reticulum, stress, heat shock proteins, osteosarcoma

Indones Biomed J. 2019; 11(2): 167-74 patients with osteosarcoma to approximately $60-70 \%$.(4) However, similar to other types of solid tumours, many osteosarcoma patients still respond poorly to chemotherapy, with the risk of local relapse or distant metastasis.(5)

A few studies have reported successful hyperthermic treatment for osteosarcoma in terms of inhibition of tumour proliferation (6), induction of apoptosis, and reduced migration of osteosarcoma cells $(7,8)$. Furthermore, a sudy reported that hyperthermia with preoperative chemotherapy for isolated limb perfusion could produce a better response 
than chemotherapy alone.(9) Growing evidences suggests that hyperthermia is one of the most promising new multidisciplinary approaches for cancer therapy, especially in light of the synergy of combined hyperthermia and chemotherapy (hyperthermochemotherapy).

Hyperthermic therapy can be either local or systemic, depending on its application. Temperatures above $40^{\circ} \mathrm{C}$ are toxic to cancer cells such as prostate carcinoma (PC)3 (10), melanoma and non-melanoma skin cancer cells (11), and human osteosarcoma cells (6). Under heat stress, the cells respond by up regulating the expression of heat shock proteins (Hsps), notably Hsp90 and 70, which help to protect against heat-induced protein unfolding. Hsp90 has been reported to play an important role in transcriptional control of the unfolded protein response (UPR) by associating with protein kinase RNA-like endoplasmic reticulum (ER) kinase (PERK) and inositol-requiring protein-1 (IRE1) to maintain protein stability.(12) Hsp90 thus represents an attractive target for cancer treatment because of its role in stabilising many client oncoproteins.(13) There are two major forms of Hsp90 which are Hsp90 $\alpha$ and Hsp90 $\beta$, that can play roles in cell differentiation, apoptosis and proliferation.(14) Hsp90 $\alpha$ is stress-inducible and has higher expression level in many types of cancer.(15) On the other hand, overexpression of Hsp27 was reported to suppress tumour migration under hyperthermic conditions.(16)

Cold inducible RNA binding protein (CIRBP) and RNA binding motif protein 3 (RBM3) are cold shockinducible proteins that act as RNA chaperones and regulate translation-transcription during hyperthermia. (17) Knockdown of cold-shock proteins was reported to enhance the sensitivity of tumour cells to chemotherapy. $(17,18)$ On the other hand, CIRBP played an important role in protecting the mouse $\mathrm{BALB} / 3 \mathrm{~T} 3$ cells from apoptosis induced by tumour necrosis factor- $\alpha$-induced apoptosis.(19)

However, the heat shock response is also temperature dependent and may be inhibited above a certain temperature threshold, promoting cell death. Furthermore, the duration of hyperthermia may also be important. Too short duration for proper heating may only inhibit the expression and action of Hsps temporarily. Overall, the mechanism underlying the induction of cell death by short-term severe hyperthermia in osteosarcoma cells remains poorly understood. The aim of the present study is to investigate the effect of short-term severe hyperthermia on cell viability, heat shock response, and the mode of cell death. This effect was investigated at the molecular level by determine changes in several key apoptosis-related genes and proteins such B-cell leukemia
2 family protein (BCL2)-associated X protein (BAX), caspases 3, 7, 8, 9 and 12 and the anti-apoptotic protein as BCL-2.

\section{Methods}

\section{Cell Culture}

Osteoblast-like osteosarcoma cells MG-63 were obtained from the American Type Culture Collection (Manassas, USA). Meanwhile, phosphate-buffered saline (PBS), Dulbecco's modified eagle medium: nutrient mixture F-12 (DMEM/F-12), foetal bovine serum, accutase, trypan blue and penicillin-streptomycin were purchased from Life Technologies (Grand Island, USA). MG-63 cells were cultured in DMEM/F-12 with $10 \%$ fetal bovine serum and $1 \%$ penicillin-streptomycin at a seeding density of $10^{4}$ cells/ $\mathrm{cm}$ in $75 \mathrm{~mL}$ flask. Severe hyperthermia group was treated at $45^{\circ} \mathrm{C}$ for $1 \mathrm{~h}$ and then recovered for $72 \mathrm{~h}$ at $37^{\circ} \mathrm{C}$ in a humidified $\mathrm{CO}_{2}$ incubator. Control group was maintained at $37^{\circ} \mathrm{C}$ for the same period of time.

\section{Cell Viability}

The cells were cultured in 96-well plates at a concentration of $5 \times 10^{3} /$ well in $100 \mathrm{uL}$ of full medium. The 3-(4,5-dimethylthiazol-2-yl)-5-(3-carboxymethoxyphenyl)2-(4-sulfophenyl)-2H-tetrazolium) (MTS) assay was used to measure the cell viability according to the manufacturer's instructions (Promega, Madison, USA). To perform the assay, $100 \mu \mathrm{L}$ was added to each well and incubated for $4 \mathrm{~h}$ at $37^{\circ} \mathrm{C}$ in a humidified $\mathrm{CO}_{2}$ incubator. The colour changes due to production of formazan crystal was measured by using Biomek ${ }^{\circledR}$ FX enzyme-linked immunosorbent assay (ELISA) reader (Beckman, Brea, USA) at $490 \mathrm{~nm}$.

\section{Flow Cytometric Measurement of Apoptosis}

A commercial Annexin V-FITC kit (Beckman Coulter, Marseille, France) was used to detect apoptotic cells. MG-63 cells were seeded at a density of $10^{4} \mathrm{cells} / \mathrm{cm}^{2}$ in T-25 flasks (Orange Scientific, Braine-l'Alleud, Belgium) and allowed to attach overnight. The severe hyperthermia treatment was done as mentioned above. After that the cells were detached by using accutase, washed with icecold PBS, and centrifuged for $5 \mathrm{~min}$ at $500 \mathrm{x}$ g at $4{ }^{\circ} \mathrm{C}$. The cell pellets were suspended in ice-cold $1 \mathrm{x}$ binding buffer to $5 \times 10^{5}-5 \times 10^{6}$ cells. Following gentle vortex, $100 \mu \mathrm{L}$ of cell suspension was stained with $5 \mu \mathrm{L}$ of propidium iodide (PI) and $1 \mu \mathrm{L}$ of Annexin V-FITC solution for $15 \mathrm{~min}$. This mixture was incubated on ice in dark room. The analysis 
was performed using a flow cytometer (Becton Dickinson, California, USA).

\section{Caspases Activity}

Activities of caspases 3/7, 8 and 9 were measured using a luminescence-based assay (Promega). Cells were seeded at $5 \times 10^{3}$ cells $/ 100 \mu \mathrm{L}$ full medium per well in white 96 -well plates and left to attach overnight at $37^{\circ} \mathrm{C}$. The next day the cells were exposed to $1 \mathrm{~h}$ of severe hyperthermia followed by $72 \mathrm{~h}$ recovery at normal temperature. At the end of the incubation time, $100 \mu \mathrm{L}$ of caspase reagent was added. The luminescence signal was measured using a plate reader (Perkin Elmer, Waltham, USA). Caspase 4 and 12 activities were determined by fluorometric assay (Biovision, Milpitas, USA) according to the manufacturer's instructions.

\section{Gene Expression Analysis by Polymerase Chain Reaction (PCR) Array}

Gene expression levels of capsases 8, 9 and 3, BCL-2, BAX, RBM3, CIRBP, Hsp70 and Hsp27 were analysed using a PCR array (Qiagen, Hilden, Germany), with glyceraldehyde 3-phosphate dehydrogenase and hypoxanthine phospho-ribosyltransferase 1 as reference genes. Briefly, total RNA was extracted from MG-63 cells using a RNA mini kit (Qiagen). RNA purity was determined using NanoDrop (Thermo Scientific, Wilmington, USA) and RNA quality was checked with the Agilent 2100 Bioanalyzer (Agilent, Santa Clara, USA). RNA samples with RNA integrity number $<7$ were excluded. An RT ${ }^{2}$ First Strand Kit was used to eliminate genomic contamination and for complementary DNA synthesis (Qiagen). One $\mu \mathrm{g}$ of total RNA was reverse transcribed in a $20 \mu \mathrm{L}$ mixture of $\mathrm{RT}^{2}$ First Strand Kit for each reaction, according to the manufacturer's protocol. One $\mu \mathrm{L}$ of the obtained complementary DNA was loaded into an $\mathrm{RT}^{2}$ profiler well after mixing with $\mathrm{RT}^{2}$ PCR master mix (total volume $25 \mu \mathrm{L}$ ) (SABioscience, Maryland, USA) 96-well PCR array plates (CAPH10449) and amplified using an iQ 5 Real Time PCR detection system (Bio-Rad, Hercules, USA).

\section{ELISA Test}

Protein expression levels of Hsp70, Hsp27 and Hsp90 $\alpha$ were determined according to the manufacturers' instructions, using commercial ELISA kits from Abcam (Cambridge, UK), Assaypro (Missouri, USA), and eBioscience (San Diego, USA), respectively. In brief, cells were harvested with accutase after treatment and washed twice with icecold PBS and centrifuged for $5 \mathrm{~min}$ at $500 \mathrm{x}$ g at $4{ }^{\circ} \mathrm{C}$. The cell pellets were lysed in $150 \mu \mathrm{L}$ of extraction buffer after adding halt protease and phosphatase inhibitor cocktail from Fisher Scientific (Lenexa, USA). The protein quantity was determined using a NanoDrop 2000c Spectrophotometer (Thermo Scientific). Colorimetric detection was determined by reading the absorbance at 450 nm (Perkin Elmer).

\section{Statistical Analysis}

Data were expressed as mean \pm standard deviation of three separate experiments. All data were tested for normality. Statistical analysis was performed by independent sample t-tests. A global significance level of $p<0.05$ was used for all analyses. Statistical analyses were performed using SPSS version 17.0 (SPSS Inc., Chicago, USA) for all assays except for PCR array data. PCR array data were analysed through the SABioscience website (http://pcrdataanalysis. sabiosciences.com/pcr/arrayanalysis.php) to calculate the $p$-values.

\section{Results}

\section{Severe Hyperthermia Reduced Cell Viability, Induced} Apoptosis, and Upregulated BAX Gene Expression

In osteosarcoma cells, severe hyperthermia significantly reduced cell viability after $72 \mathrm{~h}$ of recovery at $37^{\circ} \mathrm{C}$ (Figure 1A). The pro-apoptotic marker (BAX) was upregulated slightly in severe hyperthermia group (Figure 1B), but the increase was not significant $(p>0.05)$. BCL-2 mRNA was downregulated in severe hyperthermia group in significant manner $(p<0.01)$.

MTS results were confirmed by flow cytometric measurement of Annexin V/PI-labelled MG-63 cells, which also showed significant reductions in cell viability in the severe hyperthermia group. Severe hyperthermia significantly induced early and late apoptosis after the 72 $\mathrm{h}$ recovery period at $37^{\circ} \mathrm{C}$ (Figure $1 \mathrm{C}$ and $1 \mathrm{D}$ ). These data indicate that severe hyperthermia caused prolonged stress associated with increased apoptosis.

\section{Recovery Period After Short-term Severe Hyperthermia Increases Caspase Activities}

Activity of caspases 3/7, 4, 8, 9 and 12 were significantly increased after $72 \mathrm{~h}$ of recovery at $37^{\circ} \mathrm{C}(p<0.05)$ (Figure $2 \mathrm{~A})$. On the other hand, there was no significant difference in the effects of severe hyperthermia on gene expression of caspases 8,9 and 3 ( $p>0.05$ ) (Figure 2B). 
A

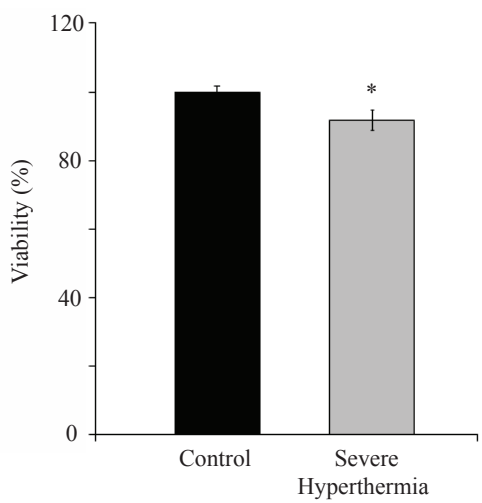

C

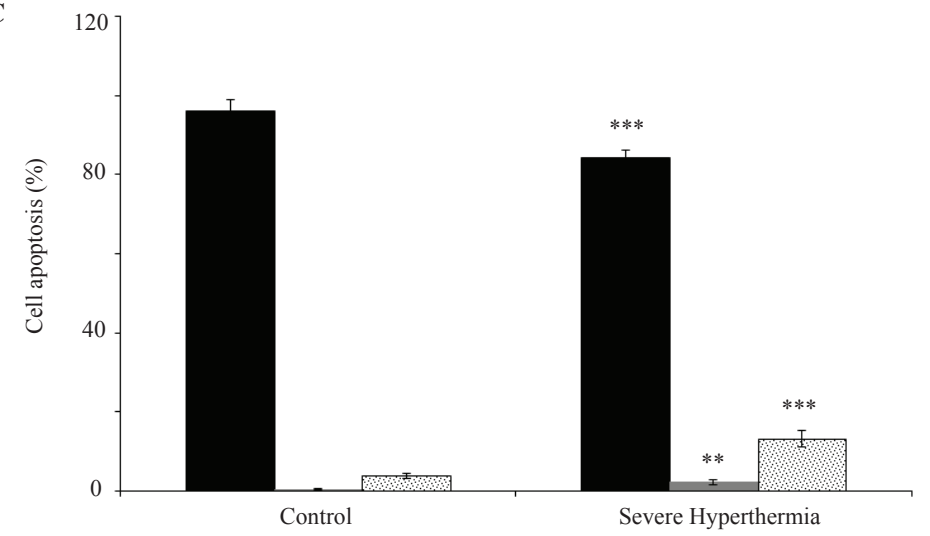

B 1.5 -

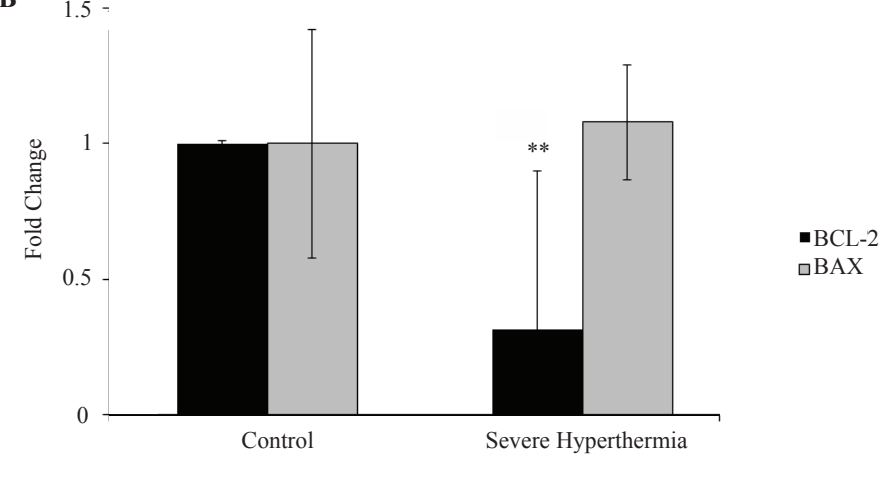

- Viable

- Early apoptosis

[. Late apoptosis/necrosis
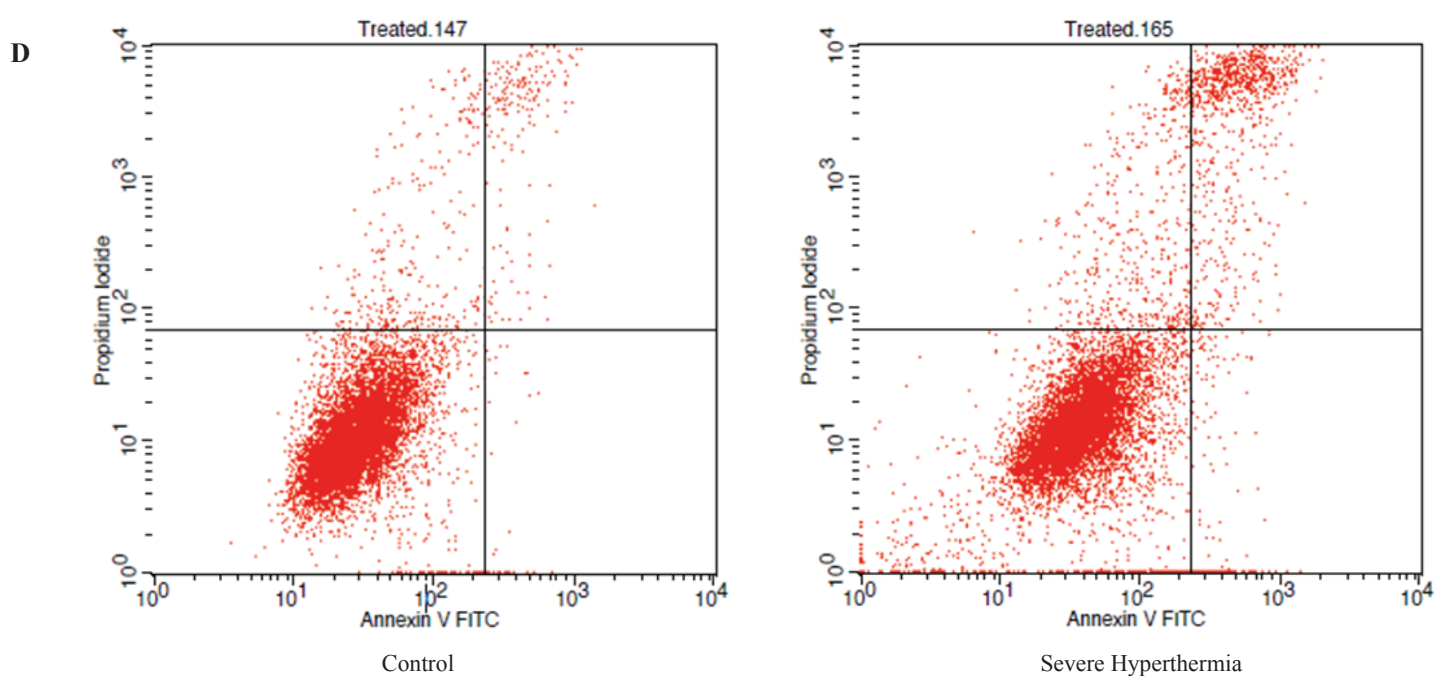

Figure 1. The effect of severe hyperthermia on various markers. A: the effect of severe, short-term hyperthermia on MG-63 cell viability; B: the effect of severe, short-term hyperthermia on expression of BCL-2 and BAX mRNA; C: the effect of severe, short-term hyperthermia on cell apoptosis percentage (data are expressed as mean $\pm \mathrm{SD}, \mathrm{n}$ equals three replicates, independent sample $\mathrm{t}$-test was used and significance was set at $* p<0.05, * * p<0.01$ and $* * * p>0.001)$; D: contour diagram of Annexin V/PI Flow Cytometry (lower left quadrants indicate viable cells, excluding PI and negative for Annexin V binding; the upper right quadrants contain the nonviable, necrotic cells and late apoptotic positive for Annexin V and PI uptake; lower right quadrants represent the early apoptotic cells, Annexin V positive and PI negative).

Severe Hyperthermia Upregulates Hsp70 and 27 but Downregulates Hsp90a and CIRBP

Protein levels of Hsp70 and 27 were significantly up regulated in the severe hyperthermia group $(p<0.001$ and $p<0.01$, respectively), while Hsp90 $\alpha$ level was significantly lower than in the negative control cells $(p<0.01)$ (Figure 3A). CIRBP transcript were downregulated by severe hyperthermia, while RBM3 expression was not significantly affected (Figure 3B). Hsp27 mRNA was upregulated significantly after $72 \mathrm{~h}$ recovery (Figure $3 \mathrm{~B}$ ). 
A

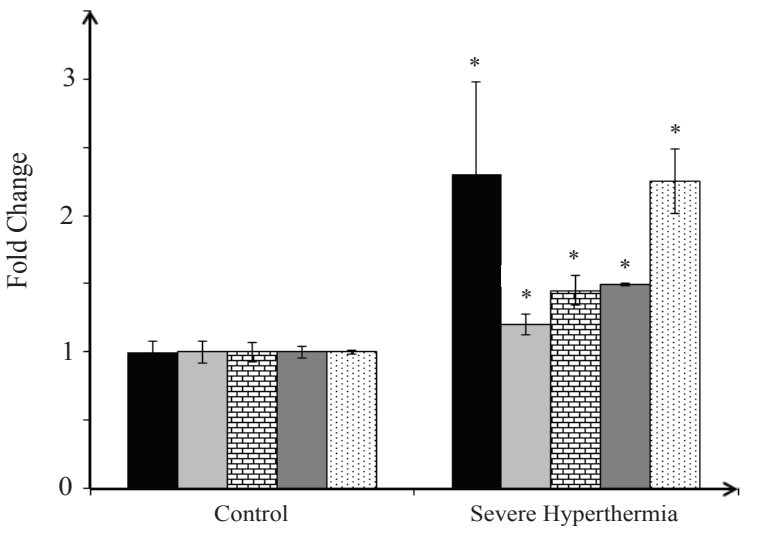

B

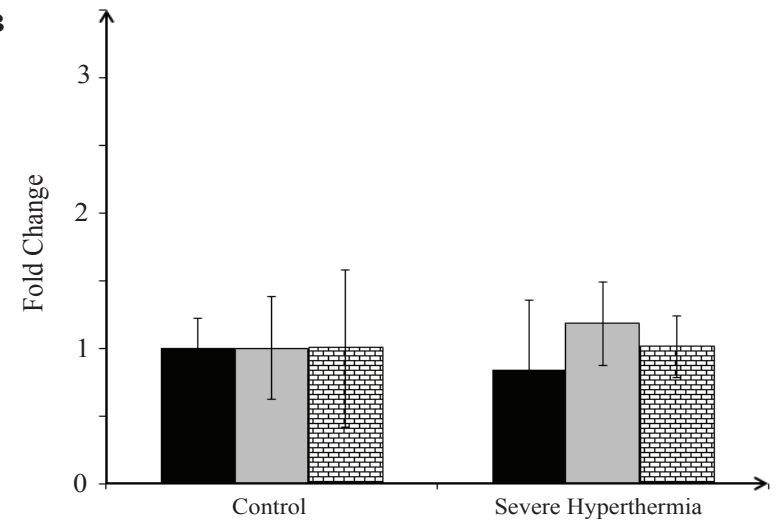

Discussion

The current study showed that severe hyperthermia induced apoptosis after $72 \mathrm{~h}$ of recovery, with rates $16 \%$, associated with a significant reduction in the viability of osteosarcoma cells. Severe hyperthermia also decreased BCL-2 mRNA and increased BAX mRNA expression and activated caspase $3 / 7$, supporting its role in inducing apoptosis. BAX is a pro-apoptotic protein found in the cytosol of cells, which in response to apoptotic stimuli translocate to the outer mitochondrial membrane (20) to induce mitochondrial-membrane permeabilisation (21) and cytochrome c release (22), which in turn activate caspase 9. In contrast, BCL-2 is an anti-apoptotic protein, which has been shown to prevent the release of cytochrome $\mathrm{c}$ and stabilise the outer mitochondrial membrane following stimulation with several types of apoptosis-inducing factors in animal cells, including chemotherapeutic agents. $(23,24)$ Our results showed that severe hyperthermiainduced apoptosis, increased BAX and deceased BCL-2 gene transcription, indicating the potential involvement of mitochondria-mediated apoptosis (intrinsic pathway).
- Casp-3/7

$\square$ Casp-8

$\boxplus$ Casp-9

$\square$ Casp-4

$\square$ Casp-12

- Casp-3

$\square$ Casp-8

m Casp-9

Caspases 4 and 12 have been reported to be ER stressspecific caspases able to induce apoptosis in human cells. $(25,11)$ Previous study found that hyperthermia induced caspase 3-dependent apoptosis, independent of classical pathway of apoptosis where caspase 3 is activated through either caspase 9 or 8.(11) They demonstrated that caspase 3 activation was stimulated through ER-mediated apoptosis. Another study was conducted on in renal epithelial cells and mouse embryonic fibroblasts and reported that apoptotic protease-activating factor 1 and mitochondria were triggered ER stress-induced cell death.(26) Another study reported that ER stress-induced apoptosis of B-chronic lymphocytic leukaemia cells was triggered by caspase 4 , which in turn activated caspase 8 , followed by activation of caspase 3.(27) In the present study, caspases 3/7, 4, 8,9 and 12 were significantly increased in the severe hyperthermia-recovered group compared with the control group. There are two possible mechanisms, first is caspase 4 activates caspase 8, which then activates caspases 3 and 9 , and combination of the intrinsic and extrinsic pathways of apoptosis together with ER stress. The prolonged ER stress lead to cell death due to overwhelming conditions, when the misfolded protein load is higher and more than the 
A

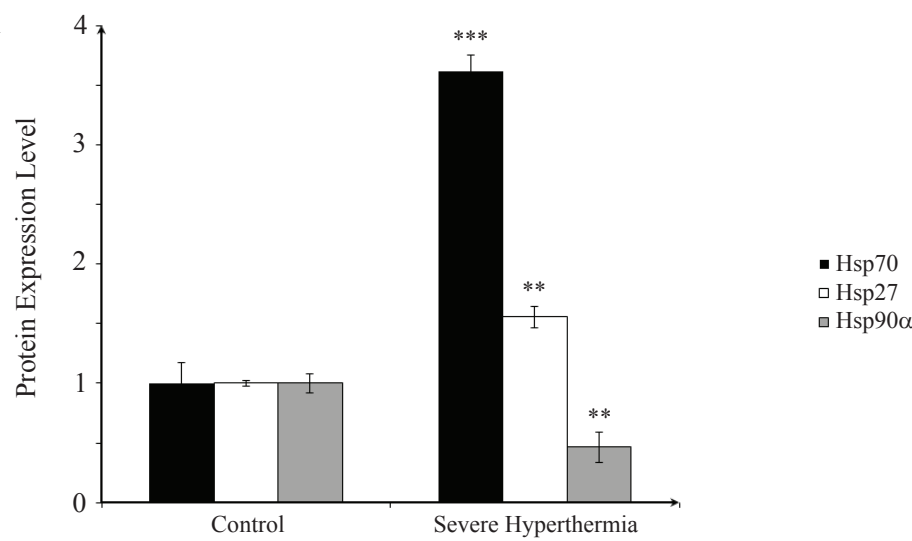

B

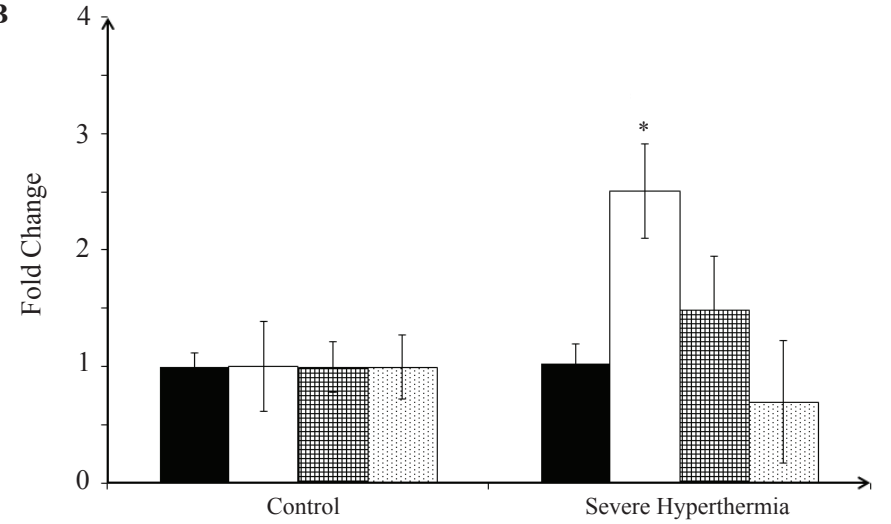

- Hsp70 $\square$ Hsp27 由 RBM3 $\square$ CIRBP
Figure 3. The effect of hyperthermia on expression of heat and cold shock proteins. A: data for protein expression; B: mRNA expression, datarepresentmeanfold change $\pm \mathrm{SD}$, $\mathrm{n}$ equals three replicates, independent sample $\mathrm{t}$-test was used and significance was set at ${ }^{*} p<0.05, * * p<0.01,{ }^{*} * * p<0.001$.
ER folding capacity.(28) The findings of the present study suggest that severe hyperthermia results in the generation of misfolded proteins that exceeds the chaperoning activity of Hsps.

Hsps play many roles in the cell, including assisting in the stabilisation and folding of numerous client proteins. These Hsps are increased in normal cells under stress situations to provide cellular protection.(29) Hsp90 represents an attractive target for cancer treatment because of its role in stabilising many client oncoproteins.(13) Hsp90 has also been reported to play an important role in the transcriptional arm of the UPR, because it is associated with maintaining the stability of PERK and IRE1.(12) Moreover, Hsp90 $\alpha$ was shown to be localised at the site of DNA damage to aid stabilisation of the DNA-repair system.(30) In the present study, Hsp90 $\alpha$ was significantly downregulated after recovery from severe hyperthermia, which might be attributed to sustained ER stress. A previous study showed that the Hsp90 inhibitor PU-H71 induced ER stress and led to apoptosis in many cancer cell lines.(13) Furthermore, apoptosis through the mitochondrial pathway was associated with downregulation of BCL-2 and activation of BAX.(13) Our results were consistent with this previous study in terms of trends in caspase activation, and
BCL-2 and BAX mRNA expression. Interestingly, Hsp90 inhibition by geldanamycin or 17-AAG was reported to induce ER stress-mediated apoptosis (31), similar to the findings of another study, which showed that the Hsp90 inhibitor PU-H71-induced ER stress and led to apoptosis in many cancer cell lines (13).

Overexpression of Hsp27 was reported to suppress tumour migration under hyperthermic conditions.(16) This effect was attributed to the suppression of autocrine motility factor. A recent study showed that overexpression of Hsp27 was associated with cell cycle arrest and increased gemcitabine sensitivity in pancreatic cancer cells (32), while Hsp70 expression was associated with a good response to chemotherapy in osteosarcoma patients (33). Furthermore, hyperthermia caused Hsp70 upregulation and reduced viability of osteosarcoma cells (6), consistent with the results of the current study in which severe hyperthermia caused upregulation of Hsp70 and Hsp27 at both the protein and mRNA levels after recovery.

In the present study, severe hyperthermia resulted in downregulation of CIRBP, which could explain the significant cell death. Several studies found that RBM3 expression and its nuclear localisation were associated with improved survival in many types of cancer cells, including 
ovarian cancer (34), breast cancer (35), malignant melanoma (36), and prostate cancer (37). Furthermore, a link between RBM3 expression and increased sensitivity to cisplatin was observed in ovarian cancer cells.(34) In the present study, induced apoptosis and reduced cell viability under severe hyperthermic conditions might be attributed to upregulation of RBM3 and downregulation of CIRBP gene expression. One study found that overexpression of RBM3 in PC3 cells greatly attenuated their stem cell-like features.(38) Induction of RBM3 in osteoblast cells under hypothermia resulted in stabilisation of mRNA and increased transcription of bone-function markers, such as alkaline phosphatase and osteocalcin.(39) The findings of these studies indicate that RBM3 promotes cancer cell differentiation and reduces cell proliferation, as indicated by the results of the MTS assay in our study. However, further studies to determine protein levels are needed to allow conclusions on the roles of coldshock proteins to be reached.

\section{Conclusion}

In conclusion, severe hyperthermia leads to induction of apoptosis in osteosarcoma cells and may result in prolonged ER stress and caspases activation. Hyperthermia also induces ER stress, indicated by reduced expression of Hsp90 and increased activation of both caspases 4 and 12. Further studies are needed to identify the precise mechanisms responsible for short-term of severe hyperthermia-induced apoptosis.

\section{Acknowledgements}

We would also like to acknowledge all the staff of the Institute of Medical Molecular Biotechnology (IMMB) for their assistance in the development of this article.

This study was supported by the Malaysian Ministry of Higher Education (MOHE) for the Fundamental Research Grant Scheme (FRGS), project code: 600-RMI/FRGS 5/3 (109/2013).

\section{References}

1. Mohanty S, Inchara Y, Crasta JA, Ananthamurthy A. An unusual case of primary osteosarcoma of the rib in an adult. Indian J Med Paediatr Oncol. 2010; 31: 18-20.
2. López-Martínez J, García-Sandoval P, Fernández-Hernández J, Valcárcel-Díaz A. Functionality and osteointegration of bone allografts in long bone osteosarcomas. Acta Ortop Mex. 2012; 26: $30-4$.

3 .Hogendoorn P, Athanasou N, Bielack S, De Alava E, Dei Tos AP, Ferrari S, et al. Bone sarcomas: ESMO Clinical Practice Guidelines for diagnosis, treatment and follow-up. Ann Oncol. 2010; 21 (Suppl 5): v204-13.

4. Wang YH, Xiong J, Wang SF, Yu Y, Wang B, Chen YX, et al. Lentivirus-mediated shRNA targeting insulin-like growth factor-1 receptor (IGF-1R) enhances chemosensitivity of osteosarcoma cells in vitro and in vivo. Mol Cell Biochemy. 2010; 341: 225-33.

5. Kobayashi E, Hornicek FJ, Duan Z. MicroRNA involvement in osteosarcoma. Sarcoma. 2012; 2012: 359739. doi: $10.1155 / 2012 / 359739$.

6. Trieb K, Blahovec H, Kubista B. Effects of hyperthermia on heat shock protein expression, alkaline phosphatase activity and proliferation in human osteosarcoma cells. Cell Biochem Funct. 2007; 25: 669-72.

7. Hou CH, Lin FL, Hou SM, Liu JF. Hyperthermia induces apoptosis through endoplasmic reticulum and reactive oxygen species in human osteosarcoma cells. Int J Mol Sci. 2014; 15: 17380-95.

8. Rong Y, Mack P. Apoptosis induced by hyperthermia in Dunn osteosarcoma cell line in vitro. Int J Hyperthermia. 2000; 16: 19-27.

9. Nakano H, Tateishi A, Miki H, Imamura T, Cho S, Abe S, et al. Hyperthermic isolated regional perfusion for the treatment of osteosarcoma in the lower extremity. Am J Surg. 1999; 178: 27-32.

10. Kalamida D, Karagounis IV, Mitrakas A, Kalamida S, Giatromanolaki A, Koukourakis MI. Fever-range hyperthermia vs. hypothermia effect on cancer cell viability, proliferation and HSP90 expression. PloS One. 2015; 10: e0116021. doi: 10.1371/journal.pone.0116021.

11. Shellman YG, Howe WR, Miller LA, Goldstein NB, Pacheco TR, Mahajan RL, et al. Hyperthermia induces endoplasmic reticulummediated apoptosis in melanoma and non-melanoma skin cancer cells. J Invest Dermatol. 2008; 128: 949-56.

12. Marcu MG, Doyle M, Bertolotti A, Ron D, Hendershot L, Neckers L. Heat shock protein 90 modulates the unfolded protein response by stabilizing IRE1 $\alpha$. Mol Cell Biol. 2002; 22: 8506-13.

13. Gallerne C, Prola A, Lemaire C. Hsp90 inhibition by PU-H71 induces apoptosis through endoplasmic reticulum stress and mitochondrial pathway in cancer cells and overcomes the resistance conferred by Bcl-2. Biochim Biophys Acta. 2013; 1833: 1356-66.

14. Sreedhar AS, Kalmár É, Csermely P, Shen YF. Hsp90 isoforms: functions, expression and clinical importance. FEBS Let. 2004; 562: 11-5.

15. Csermely P, Schnaider T, So C, Prohászka Z, Nardai G. The 90$\mathrm{kDa}$ molecular chaperone family: structure, function, and clinical applications. A comprehensive review. Pharmacol Ther. 1998; 79: 129-68.

16. Nakajima K, Yanagawa T, Watanabe H, Takagishi K. Hyperthermia reduces migration of osteosarcoma by suppression of autocrine motility factor. Oncol Rep. 2012; 28: 1953-8.

17. Dresios J, Aschrafi A, Owens GC, Vanderklish PW, Edelman GM, Mauro VP. Cold stress-induced protein Rbm3 binds 60S ribosomal subunits, alters microRNA levels, and enhances global protein synthesis. Proc Natl Acad Sci. 2005; 102: 1865-70.

18. Zeng Y, Kulkarni P, Inoue T, Getzenberg RH. Down-regulating cold shock protein genes impairs cancer cell survival and enhances chemosensitivity. J Cell Biochem. 2009; 107: 179-88.

19. Sakurai T, Itoh K, Higashitsuji H, Nonoguchi K, Liu Y, Watanabe $\mathrm{H}$, et al. Cirp protects against tumor necrosis factor- $\alpha$-induced 
apoptosis via activation of extracellular signal-regulated kinase. Biochim Biophys Acta. 2006; 1763: 290-5.

20. Goping S, Gross A, Lavoie JN, Nguyen M, Jemmerson R, Roth K, et al. Regulated targeting of BAX to mitochondria. J Cell Biol. 1998; 143: 207-15.

21. Kuwana T, Newmeyer DD. Bcl-2-family proteins and the role of mitochondria in apoptosis. Curr Opin Cell Biol. 2003; 15: 691-9.

22. Wei MC, Zong WX, Cheng EHY, Lindsten T, Panoutsakopoulou V, Ross AJ, et al. Proapoptotic BAX and BAK: a requisite gateway to mitochondrial dysfunction and death. Science. 2001; 292: 727-30.

23. Nuñez G, Clarke MF. The Bcl-2 family of proteins: regulators of cell death and survival. Trends Cell Biol. 1994; 4: 399-403.

24. Reed JC. Bcl-2 and the regulation of programmed cell death. J Cell Biol. 1994; 124: 1-6.

25. Hitomi J, Katayama T, Eguchi Y, Kudo T, Taniguchi M, Koyama Y, et al. Involvement of caspase-4 in endoplasmic reticulum stressinduced apoptosis and A $\beta$-induced cell death. J Cell Biol. 2004; 165: $347-56$

26. Shiraishi H, Okamoto H, Yoshimura A, Yoshida H. ER stressinduced apoptosis and caspase-12 activation occurs downstream of mitochondrial apoptosis involving Apaf-1. J Cell Sci. 2006; 119: 3958-66.

27. Rosati E, Sabatini R, Rampino G, De Falco F, Di Ianni M, Falzetti $\mathrm{F}$, et al. Novel targets for endoplasmic reticulum stress-induced apoptosis in B-CLL. Blood. 2010; 116: 2713-23.

28. Sano R, Reed JC. ER stress-induced cell death mechanisms. Biochim Biophys Acta. 2013; 1833: 3460-70.

29. Schmitt E, Gehrmann M, Brunet M, Multhoff G, Garrido C. Intracellular and extracellular functions of heat shock proteins: repercussions in cancer therapy. J Leukoc Biol. 2007; 81: 15-27.

30. Quanz M, Herbette A, Sayarath M, de Koning L, Dubois T, Sun JS, et al. Heat shock protein $90 \alpha$ (Hsp90 $\alpha$ ) is phosphorylated in response to DNA damage and accumulates in repair foci. J Biol Chem. 2012; 287: 8803-15.

31. Taiyab A, Sreedhar AS, Rao CM. Hsp90 inhibitors, GA and 17AAG, lead to ER stress-induced apoptosis in rat histiocytoma. Biochem Pharmacol. 2009;78: 142-52.
32. Guo Y, Ziesch A, Hocke S, Kampmann E, Ochs S, De Toni EN, et al. Overexpression of heat shock protein 27 (HSP 27) increases gemcitabine sensitivity in pancreatic cancer cells through S-phase arrest and apoptosis. J Cell Mol Med. 2015; 19: 340-50.

33. Trieb K, Lechleitner T, Lang S, Windhager R, Kotz R, Dirnhofer S. Heat shock protein 72 expression in osteosarcomas correlates with good response to neoadjuvant chemotherapy. Hum Pathol. 1998; 29: $1050-5$

34. Ehlén Å, Brennan DJ, Nodin B, O'connor DP, Eberhard J, AlvaradoKristensson M, et al. Expression of the RNA-binding protein RBM3 is associated with a favourable prognosis and cisplatin sensitivity in epithelial ovarian cancer. J Transl Med. 2010; 8: 78. doi: 10.1186/1479-5876-8-78.

35. Jögi A, Brennan DJ, Rydén L, Magnusson K, Fernö M, Stål O, et al. Nuclear expression of the RNA-binding protein RBM3 is associated with an improved clinical outcome in breast cancer. Mod Pathol. 2009; 22: 1564-74

36. Jonsson L, Bergman J, Nodin B, Manjer J, Pontén F, Uhlén M, et al. Low RBM3 protein expression correlates with tumour progression and poor prognosis in malignant melanoma: an analysis of 215 cases from the Malmö Diet and Cancer Study. J Transl Med. 2011; 9: 114. doi: 10.1186/1479-5876-9-114.

37. Jonsson L, Gaber A, Ulmert D, Uhlén M, Bjartell A, Jirström K. High RBM3 expression in prostate cancer independently predicts a reduced risk of biochemical recurrence and disease progression. Diagnostic Pathology. 2011; 6: 91. doi: 10.1186/17461596-6-91.

38. Zeng Y, Wodzenski D, Gao D, Shiraishi T, Terada N, Li Y, et al. Stress response protein RBM3 attenuates the stem-like properties of prostate cancer cells by interfering with CD44 variant splicing. Cancer Res. 2013; 73: 4123-33.

39. Aisha M, Nor-Ashikin M, Sharaniza A, Nawawi H, Kapitonova M, Froemming G. Short-term moderate hypothermia stimulates alkaline phosphatase activity and osteocalcin expression in osteoblasts by upregulating Runx2 and osterix in vitro. Exp Cell Res. 2014; 326: 46-56. 